\title{
COMMISSION 21: LIGHT OF THE NIGHT SKY
} (LUMIERE DU CIEL NOCTURNE)

\author{
PRESIDENT: Philippe Lamy \\ VICE-PRESIDENT: J. Mayo Greenberg
}

ORGANiziNG COMMITTEE: S. Bowyer, E. Dwek, Bo A. Gustafson, R. Henry, I. Mann, T. Mukai, W. Reach, A. Witt

\section{IAU GENERAL ASSEMBLY COMMISSION 21 BUSINESS MEETING - MINUTES, July 15 2003, the Sydney Convention Centre.}

Chair: The meeting was chaired by the incoming President, Bo Gustafson.

New Member: Application by Prof. Christopher Martin (USA) was endorsed.

New Officials: The commission $21 \mathrm{OC}$ voted by e-mail prior to the business meeting to endorse for President: Bo Gustafson (USA) and Vice President: Adolf Witt (USA).

The Organizing Committee was not been officially revised at the 2000 GA in Manchester but the intended composition of nine members as found of the commission website was used as the basis for the new OC. Two members, Tadashi Mukai (Japan) and William Reach (USA) have elected to resign. One member, S. Bowyer (USA) did not respond to repeated attempt to contact by e-mail and phone messages. After deliberation and after consulting the Division III president, it was agreed not to continue this member. It might be noted that Bower is a past president and that it is customary for presidents to stay on the $\mathrm{OC}$ for the triennium following their tenure as presidents. This term now has reached its end and since there was no indication from the member in question as to his desire to remain an active member of the OC it was assumed that he also desires to resign. No new members of the $\mathrm{OC}$ were proposed by the members. For this reason, to adhere to IAU new bylaws (although this is not strictly required until next triennium), and to streamline operations, the $\mathrm{OC}$ reduced to four members:
E. Dwek (USA)
P. Lamy (France)
R. Henry (USA)
I. Mann (Germany)

This decision was preceded by a debate on the national distribution where it was noted that both the new President and Vice President are active in the USA as are two of the four other members of the OC. It was however concluded that this is reasonable given the geographical distribution of current activities in the field although a Japanese member is highly desirable and a candidate is considered for this position, the official appointment will be considered for the 2006 GA in Prague. This will give the commission time to consider its future objectives while maintaining maximum flexibility to reorganize. 


\section{Working Groups}

The commission objectives to "Facilitate research in the areas of the diffuse components of the light of the night sky among the worldwide astronomical community" were reviewed and no objection was raised as to the current formulation at this time. The interpretation of the word "research" in broad terms that specifically include observations, description, and astrophysical interpretation were confirmed.

With this background and to revitalize Commission 21 activities it was agreed to form working groups on the following topics where the actual names are to be set by the WG themselves:

- Desirable observational quantities (define and rank)

- Aggregate dust structures (in honor of the memory of Prof. J.M. Greenberg, past V.P.)

- Night sky light characterization for light engineering, natural and artificial

\section{Other future Develpements}

Division III is considering a major reorganization that would reduce the number of its commissions to possibly as few as two. Commission 21 needs to consider its future in this context. For that purpose it is

my intent to form a panel to study and make recommendations for the future organization of Commission 21 activities. This panel will be appointed in a democratic fashion though member votes. Active members are expected to be responding to e-mail so for efficiency the vote will be conducted using e- mail polls alone. It is expected that the commissions under Division III will retain their current structure through the 2006-2009 triennium. Commission 21 therefore needs to revitalize its activities to be commensurate with its objectives and mandate which should make it one of the most important commissions within Division III and needs to appoint a strong leadership at the 2006 GA in Prague. It is my expectation that the panel members will form the core of this leadership and that with the new slimmer OCs all members will be elected by the commission members based on stated objectives and will have well defined roles. 